Jpn. J. Genet. (1986) 61, pp. 217-223

\title{
Chromosome inversion polymorphism in a Tunisian natural population of Drosophila melanogaster
}

\author{
By Sylvie AUlard \\ Laboratoire de Biologie et Génétique Evolutives \\ C.N.R.S., 91190, Gif-sur-Yvette, France \\ Université P. et M. Curie, Paris, France
}

(Received May 20, 1986)

\begin{abstract}
A Tunisian natural population of Drosophila melanogaster has been screened for chromosome inversion polymorphism. All 10 of the inversion types found are paracentric and autosomal. Five of these are cosmopolitan: common, $\operatorname{In}(2 \mathrm{~L}) \mathrm{t}$ and $\operatorname{In}(2 \mathrm{R}) \mathrm{NS}$, or rare, $\operatorname{In}(2 \mathrm{R}) \mathrm{Cy}, \operatorname{In}(3 \mathrm{R}) \mathrm{C}$ and $\operatorname{In}(3 \mathrm{R}) \mathrm{M}$. The others are new endemic, with the exception of $\operatorname{In}(2 \mathrm{~L}) \mathrm{Cy}$. This inversion, the break points of which are very close, both distally and proximally, to those of $\operatorname{In}(2 \mathrm{~L}) \mathrm{t}$, was never formally described in a natural population before and seemed to be only a laboratory stock rearrangement. The presence of In $(2 L) \mathrm{Cy}$ has been established unequivocally by crossing males from the Tunisian lines with virgin females from a (2L)Cy-type strain. From the results, In $(2 \mathrm{~L}) \mathrm{Cy}$ appears to exist in at least one natural population. It is possible that this chromosome sequence might occur in another population, but described as $\operatorname{In}(2 \mathrm{~L}) \mathrm{t}$ because of the close similarity of these two inversions.
\end{abstract}

\section{INTRODUCTION}

Data on the inversion chromosome polymorphism of Drosophila melanogaster have considerably increased in the last ten years. The most recent results were collected from populations of USA (Stalker 1976; Langley et al. 1977; Mettler et al. 1977; Mukai and Voelker 1977; Voelker et al. 1978), Asia (Inoue 1979; Inoue and Watanabe 1979; Inoue et al. 1980) and Australia (Knibb et al. 1981). Nearly 300 inversions are now recorded. Considering the increasing number of natural inversions reported and in view of their distribution and abundance, Ashburner and Lemeunier (1976) and Mettler et al. (1977) decided to classify the inversions of $D$. melanogaster in four classes: (i) common cosmopolitan inversions; (ii) rare cosmopolitan inversions; (iii) recurrent endemic inversions; (iv) unique endemic inversions.

Apart of few exceptions, the inversions are paracentric, autosomal and simple (Lemeunier et al. 1986). If many populations have been sampled in U.S.A., Asia and Australia, no data are known so far about North Africa, except those in Ashburner and Lemeunier (1976) in Morocco.

The purpose of this paper is to present a description of the different inver- 
sions found in a Tunisian population and to discuss the unequivocal discovery of $\mathrm{In}(2 \mathrm{~L}) \mathrm{Cy}$ whose existence in a natural population was previously doubtful.

\section{MATERIALS AND METHODS}

Wild flies were collected in the oasis of Nasr'Allah, $50 \mathrm{~km}$ South West of Kairouan (Tunisia) in Autumn 1981 and fertilized females were individually kept in vials to initiate isofemale lines. One male from each of 50 isofemale lines was mated with one virgin Canton-S female, homozygous for the cytologically standard sequence in all chromosome arms. The salivary gland of a minimum of six third instar larvae per parental male was examined. The break points of the inversions were identified by comparing photographs with the salivary gland chromosome maps drawn by Bridges (1935) and the photographic maps of Lefevre (1976).

\section{RESULTS}

Ten different inversions were detected. We named each of them by its break points in the following list:

Chromosome 2, left arm (2L)

1. In(2L)t22D3-E1; 34A8-9, common cosmopolitan

2. In(2L)Cy22D1-2; 33F5-34A1, see comments in the text

3. In(2L)30A1-2; 33A3-8, new endemic found in two isofemale lines

Chromosome 2, right arm (2R)

4. In(2R)NS52A2-B1; 56F9-13, common cosmopolitan

5. In(2R)Cy42A2-3; 58A4-B1, rare cosmopolitan

6. In(2R)45F3-8; 59B, new unique endemic

Chromosome 3, left arm (3L)

7. $\operatorname{In}(3 \mathrm{~L}) 69 \mathrm{~A}-\mathrm{B} ; 73 \mathrm{~A}$, new unique endemic

8. In(3L)69A; 79E5-8, new unique endemic

Chromosome 3, right arm (3R)

9. In(3R)C92D1-E1; 100F2-3, rare cosmopolitan

10. In(3R)M86F; $100 \mathrm{E}$, rare cosmopolitan.

$\operatorname{In}(2 \mathrm{~L}) \mathrm{t}, \operatorname{In}(2 \mathrm{R}) \mathrm{NS}, \operatorname{In}(3 \mathrm{~L}) \mathrm{P}$ and $\mathrm{In}(3 \mathrm{R}) \mathrm{P}$ are the four common cosmopolitan inversions of $D$. melanogaster found in most natural populations investigated. The first two have also been detected in this Tunisian population, in frequencies of 13 and 7 percent, respectively (Table 1). But none of the 50 isofemale lines has revealed the two common cosmopolitan rearrangements of the third chromosome, $\operatorname{In}(3 \mathrm{~L}) \mathrm{P}$ and $\operatorname{In}(3 \mathrm{R}) \mathrm{P}$. The only inversions found on this chromo- 
Table 1. Nature and frequencies (\%) of the inversions found in the Nasr'Allah population (Tunisia).

\begin{tabular}{|c|c|c|c|c|c|c|c|c|}
\hline \multicolumn{6}{|c|}{ chromosome $2(\mathrm{~N}=100)$} & \multicolumn{3}{|c|}{ chromosome $3(\mathrm{~N}=100)$} \\
\hline \multicolumn{3}{|c|}{ left arm } & \multicolumn{3}{|c|}{ right arm } & \multirow{2}{*}{$\begin{array}{l}\text { left arm } \\
\text { endemic* }\end{array}$} & \multicolumn{2}{|c|}{ right arm } \\
\hline $\operatorname{In}(2 \mathrm{~L}) \mathrm{t}$ & $\operatorname{In}(2 \mathrm{~L}) \mathrm{Cy}$ & others* & In $(2 R) N S$ & $\operatorname{In}(2 \mathrm{R}) \mathrm{Cy}$ & endemic* & & $\operatorname{In}(3 R) C$ & $\operatorname{In}(3 R) M$ \\
\hline 13 & $(10)$ & (2) & 7 & 6 & (1) & (2) & 3 & 6 \\
\hline
\end{tabular}

$\mathrm{N}$ : number of chromosomes examined

* : endemic inversions, description in the text

( ): number of endemic inversions

CHROMOSOME 2

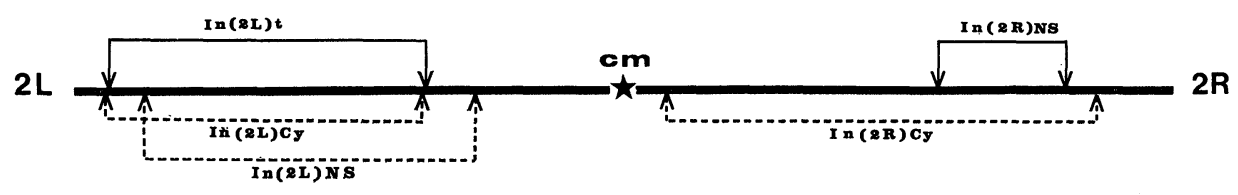

CHROMOSOME 3

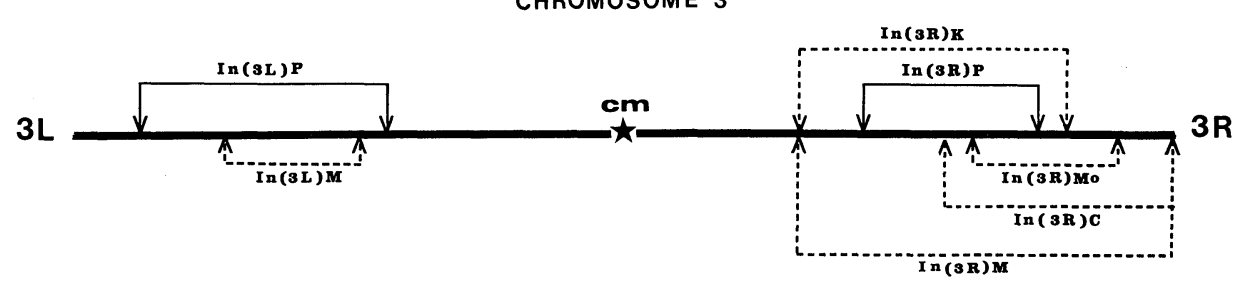

Fig. 1. Location of the cosmopolitan and In(2L)Cy inversions of D. melanogaster.

some were two new unique endemic ones and two rare cosmopolitan ones, $\operatorname{In}(3 R) C$ and $\operatorname{In}(3 R) M(3$ and 6 percent, respectively). The absence of $\operatorname{In}(3 R) P$ is very surprising because it is the most frequent and cosmopolitan of the four common inversions of $D$. melanogaster, found in all natural populations so far screened.

Another interesting finding is the discovery of $\operatorname{In}(2 \mathrm{~L}) \mathrm{Cy}$, with a frequency of 10 percent. This inversion was supposed not to exist in any natural populations (Ashburner and Lemeunier 1976). A great similarity exists between the common cosmopolitan inversion $\mathrm{In}(2 \mathrm{~L}) \mathrm{t}$ whose break points are 22D3-E1 and 34A8-9, and In(2L)Cy (22D1-2 and 33F5-34A1) (figure 1). In(2L)Cy was detected genetically by Ward (1923) as a crossover inhibitor, associated with the dominant Curly mutation. It was found in a stock composed of flies collected in Ann Arbor, Michigan, in September 1918. In(2L)Cy was thought to be only a laboratory stock rearrangement. In fact, in spite of the great number of natural populations screened, there were only very few reports of 

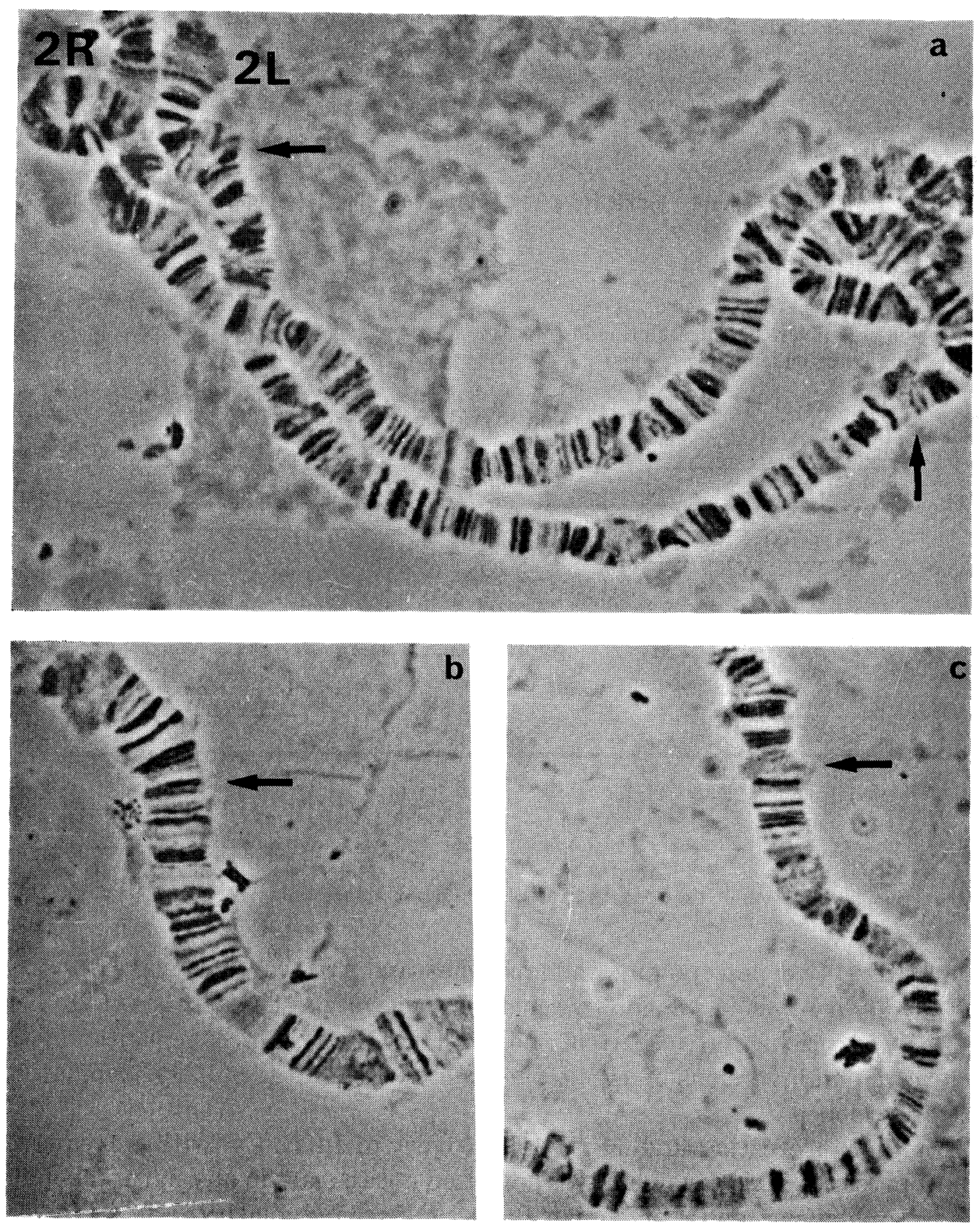

Fig. 2. Results of crosses between males from Nasr'Allah population (Tunisia) and females from a $2 \mathrm{LCy}$-type strain.

a. Heterozygous $\operatorname{In}(2 \mathrm{~L}) \mathrm{t} / \operatorname{In}(2 \mathrm{~L}) \mathrm{Cy}$

b. Homozygous $\operatorname{In}(2 \mathrm{~L}) \mathrm{Cy} / \operatorname{In}(2 \mathrm{~L}) \mathrm{Cy}$. Distal end of the left arm of the second chromosome.

c. Homozygous $\operatorname{In}(2 \mathrm{~L}) \mathrm{Cy} / \mathrm{In}(2 \mathrm{~L}) \mathrm{Cy}$. Proximal end of the left arm of the second chromosome. 
In $(2 \mathrm{~L}) \mathrm{Cy}$. When this inversion was reported, with drawings or photographs published, it was in fact $\operatorname{In}(2 \mathrm{~L}) \mathrm{t}$ (Ashburner and Lemeunier 1976). These confusions can be easily explained by the great similarity of these two inversions.

To confirm the existence of $\operatorname{In}(2 \mathrm{~L}) \mathrm{Cy}$ and $\operatorname{In}(2 \mathrm{~L}) \mathrm{t}$ in our natural Tunisian population, males from involved lines were crossed with virgin females from a (2L)Cy-type strain, originated from the Department of Genetics of the University of Göteborg (Sweden). The results are shown in figure 2. The presence of $\operatorname{In}(2 \mathrm{~L}) \mathrm{t}$ can be seen in the heterozygous larvae $\operatorname{In}(2 \mathrm{~L}) \mathrm{t} / \mathrm{In}(2 \mathrm{~L}) \mathrm{Cy}$ by a non pairing of the homologues at the distal and proximal ends of the inverted segment. Figure 2b-c shows the full homology of the left arm homologues of both the (2L)Cy-type strain and Tunisian strain. This confirms unequivocally the existence of this arrangement in this Tunisian natural population. It can be further added that this inversion was found alone without the Curly mutation.

On the same chromosome, we have also detected $\mathrm{In}(2 \mathrm{R}) \mathrm{Cy}$ that was declared as rare cosmopolitan by Mettler et al. (1977) and has been for the first time described genetically by Ward (1923), as crossover suppressor, in the same stock as $\operatorname{In}(2 \mathrm{~L}) \mathrm{Cy}$. The frequency of this arrangement is similar to that of the common cosmopolitan In(2R)NS (table 1).

\section{DISCUSSION}

The chromosomal inversion polymorphism of the Tunisian natural population of $D$. melanogaster presents different interesting aspects. First, in spite of the great number of analysed lines, the $\operatorname{In}(3 R) P$ inversion was not found. $\mathrm{In}(3 \mathrm{R}) \mathrm{P}$ is known to be the most common of the cosmopolitan inversions of this species. Even if we supposed that $\operatorname{In}(3 R) P$ was not revealed because of its very low frequency in the natural population, this would constitute in itself a peculiarity of this population as the frequencies of the common cosmopolitan $\operatorname{In}(2 \mathrm{~L}) \mathrm{t}$ and $\operatorname{In}(2 \mathrm{R}) \mathrm{NS}$ are quite significant.

Another interesting finding relates to $\operatorname{In}(2 \mathrm{~L}) \mathrm{Cy}$. The crosses carried out with the $(2 \mathrm{~L}) \mathrm{Cy}$-type strain show that this inversion occurs together with In $(2 \mathrm{~L}) \mathrm{t}$ in this Tunisian population. Hence, this provides the first clear evidence of the existence of $\mathrm{In}(2 \mathrm{~L}) \mathrm{Cy}$ in a natural population. Whether or not it occurs in other natural populations is still unclear although some of the $\operatorname{In}(2 \mathrm{~L}) \mathrm{t}$ mentioned in the literature might be $\mathrm{In}(2 \mathrm{~L}) \mathrm{Cy}$ as well (or the reverse).

It is also of interest to focus attention on $\operatorname{In}(2 \mathrm{R}) \mathrm{Cy}$. It is worth emphasizing that this inversion, that appears at a $6 \%$ frequency, is always detected in our observations in a chromosome 2 bearing in the left arm either In $(2 \mathrm{~L}) \mathrm{Cy}$ or $\operatorname{In}(2 \mathrm{~L})$ t. A significant linkage disequilibrium exists between $\operatorname{In}(2 \mathrm{~L}) \mathrm{Cy}$ and 
$\operatorname{In}(2 \mathrm{R}) \mathrm{Cy}$, but not between $\operatorname{In}(2 \mathrm{~L}) \mathrm{t}$ and $\operatorname{In}(2 \mathrm{R}) \mathrm{Cy}$ (Aulard and Lemeunier 1985). In(2R)Cy was described as crossover suppressor by Ward (1923) from the same stock and in the same chromosome as In(2L)Cy. It can be assumed that both inversions were present in the natural population from which the stock was initiated. In $(2 \mathrm{R}) \mathrm{Cy}$ was found previously in the Lincoln population (Nebr.) by Mettler et al. (1977) with In(2L)t, but without evidence of In(2L)Cy and might also occur in USSR (Dubinin et al. 1937; Grossman 1967). Data are still lacking to assess whether or not $\operatorname{In}(2 \mathrm{R}) \mathrm{Cy}$ is closely associated, or even co-adaptated, with $\operatorname{In}(2 \mathrm{~L}) \mathrm{Cy}$ or whether the co-occurrence of these two rearrangements has appeared repeatedly at random in the 1918-American and 1981-Tunisian populations. Their association might be due to the closeness of their proximal break points therefore preventing frequent recombination between them.

The author is especially grateful to Drs. F. Lemeunier and D. Lachaise for their help and criticisms of the manuscript, and to Dr. M. Ashburner for confirming the cytological interpretation of $\mathrm{In}(2 \mathrm{~L}) \mathrm{Cy}$. Thanks are also due to the Department of Genetics of the University of Göteborg (Sweden) for supplying the (2L)Cy-type strain and the Tunisian authorities for permission to collect the flies.

\section{REFERENCES}

Ashburner, M. (1967) Patterns of puffing activity in the salivary gland chromosomes of Drosophila. I. Autosomal puffing patterns in a laboratory stock of Drosophila melanogaster. Chromosoma 21, 398-428.

Ashburner, M. and Lemeunier, F. (1976) Relationships within the melanogaster species subgroup of the genus Drosophila (Sophophora). I. Inversion polymorphism in Drosophila melanogaster and Drosophila simulans. Proc. R. Soc. Lond. B 193, 137-157.

Aulard, S. and Lemeunier, F. (1985) Distribution et association des inversions chromosomiques dans trois populations naturelles de Drosophila melanogaster de France, Tunisie et Congo. Genet. Sel. Evol. 17(3), 19-38 (in French, English summary).

BRIDGES, C. B. (1935) Salivary chromosome maps with a key to the banding of the chromosomes of Drosophila melanogaster. J. of Heredity 26, 60-64.

Dubinin, N. P., Sokolov, N. N. and Tiniakov, G. G. (1937) Intraspecific chromosome variability. Biol. Zh. 6, 1007-1054. (Russian, English summary).

Grossman, A. I. (1967) Distribution of breaks limiting autosomal inversions in natural populations of Drosophila melanogaster. Genetika (USSR) 3, 53-62 (English version in Soviet Genetics 3, 31-35.

Inoue, Y. (1979) Seasonal changes of inversion frequencies of Drosophila melanogaster. An. Rpt. Nat. Inst. Genetics, Japan 29, 77-78.

INOUE, Y. and WATANABE, T. K. (1979) Inversion polymorphism in Japanese natural populations of Drosophila melanogaster. Japan J. Genetics 54, 69-82.

Inoue, Y., Tsuno, K. and Watanabe, T. K. (1980) New inversions of Drosophila melanogaster spreading in Japan. An. Rpt. Nat. Inst. Genetics, Japan 30. 88.

KnibB, W. R., OAkeshott, J. G. and Gibson, J. B. (1981) Chromosome inversion polymorphism in Drosophila melanogaster. I. Latitudinal clines and associations between inversions in Australian populations. Genetics 98, 833-847.

LANGley, C. H., Ito, K. and Voelker, R. A. (1977) Linkage disequilibrium in natural populations of Drosophila melanogaster. Seasonal variations. Genetics 86, 447-454.

LEFEVRE, G. (1976) A photographic representation and interpretation of the polytene chromo- 
somes of Drosophila melanogaster salivary glands. In: "The Genetics and Biology of Drosophila", (ed. by M. Ashburner and E. Novitsky.) Vol. la, Academic Press, London.

Lemeunier, F., David, J., Tsacas, L. and Ashburner, M. (1986) The melanogaster species group. In: "The Genetics and Biology of Drosophila", Vol. 3e. Evolution and Speciation in selected species group. (eds. M. Ashburner, H. L. Carson and J. N. Thompson Jr.)

Mettler, L. E., Voelker, R. A. and Mukai, T. (1977) Inversion clines in populations of Drosophila melanogaster. Genetics 87, 169-176.

MuKaI, T. and VoELKer, R. A. (1977) The genetic structure of natural populations of Drosophila melanogaster. XIII. Further studies on linkage disequilibrium. Genetics 86, 175-185.

Stalker, H. D. (1976) Chromosome studies in wild populations of Drosophila melanogaster. Genetics 82, 323-347.

Voelker, R. A., Cockerham, C. C., Johnson, F. M., Schaffer, H. E., Mukai, T. and Mettler, L. E. (1978) Inversions fail to account for allozyme clines. Genetics 88, 515-527.

Ward, L. (1923) The genetics of Curly wing in Drosophila. Another case of balanced lethal factors. Genetics 8, 276-300. 